\title{
Persistent immune-tolerance to non-inherited maternal antigen (NIMA) allows successful kidney transplantation in regraft patient: Case report
}

\section{Rabab A Al Attas* and Abdelhamid Liacini}

Histocompatibility and Immunogenetic Laboratory (HIL), Department of Pathology and Laboratory Medicine, King Fahad Specialist Hospital-Dammam, Kingdom of Saudi Arabia

\begin{abstract}
The introduction of non-inherited maternal HLA antigens (NIMA) into the fetus and the exposure of mother to the inherited paternal antigens (IPA) presented on fetal cells as a result of two-way traffic of cells between mother and fetus during pregnancy may affect graft responses later in life. Maternal contact with IPA can lead to activation of maternal immune system with the development of anti-paternal HLA- antibodies. On the other hand Exposure of the fetus to NIMA can lead to NIMA -specific tolerance due to immaturity of the child immune system in utero and is associated with significantly better graft survival from NIMA-mismatched sibling. The NIMA paradox is the observation that unlike transplantation from NIMA- mismatched sibling, reexposure to a transplant from mother herself (the ideal NIMA- donor) does not yield better survival, indicating that NIMA has no survival -advantage when presented on maternal graft. Studies on the effect of tolerance to non-inherited maternal antigens (NIMAs) in renal transplant recipients are generally few and looked at improved kidney graft of first transplant. Here we report an interesting combination for both effects of the same NIMA in a patient who underwent a successful second kidney transplant after exposure to repeat NIMA - mismatched graft presented on the second sibling donor.
\end{abstract}

\section{Introduction}

Kidney transplantation is the therapy of choice for patients with end stage renal disease. Graft survival is optimal when donor and recipient are fully match for the human leukocyte antigens (HLA), however due to the high degree of polymorphism of HLA, in most situation, this is not possible. Therefore haploidentical (partially matched) siblings, parents or off-spring are considered as potential donor. The patient inherits the maternal HLA-antigen (IMA) from the mother and paternal antigen (IPA) from the father. Figure 1 illustrates how a parent or sibling can share one haplotypes with the recipient and

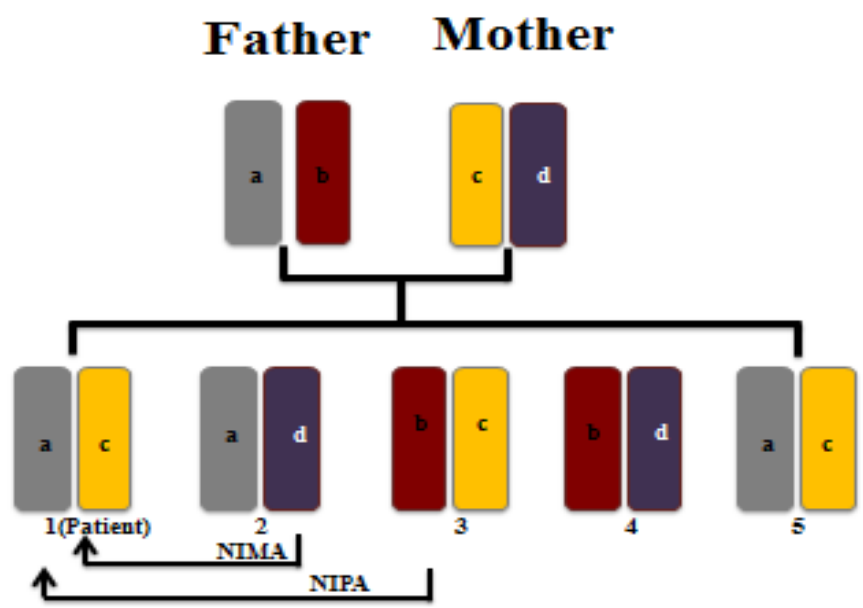

Figure 1. A scheme to designate the haplotypes of a family in which one of the offespring (patient) is a potential kidney recipient. Both parents and sibling 2 and 3 share one haplotype with the patient ( $\mathrm{a}$ and $\mathrm{c}$ respectively), the other haplotypes are considered for the patient as non-inherited maternal (NIMA) or paternal (NIPA) haplotypes ( $\mathrm{d}$ and $\mathrm{b}$ respectively). Sibling 4 does not share any haplotype,while sibling 5 is genotypicaly identical. differ for the other haplotype. When the patient is transplanted with a kidney from his mother or from a haploidentical sibling, the NIMA are the mismatched haplotype. In case the mother is transplanted from her offspring or from her husband the IPA is the mismatched haplotype.

Several studies have been performed to investigate the influence of non-inherited and inherited parental antigens on transplantation and both immunizing (especially IPA) and tolerizing (the NIMA effect) $[1,2]$. These studies have shown better graft survival of kidney grafts from sibling who were mismatched for the NIMA haplotype compared with the NIPA haplotype mismatched sibling 1 (10-year graft survival of $77 \%$ and $49 \%$ respectively). Of particular importance is the finding of Burlingham et of equal survival of sibling derived graft expressing the NIMA to HLA-identical siblings. The status of feto-maternal microchimerism that occur in utero as a result of mixing of noninherited maternal antigens which lead to co-existence of cells from two different genes in the fetus was thought to be an important factor involved in the induction of tolerance $[3,4]$.

In contrast, this effect was not present when maternal grafts were used 5. Several explanations were given for this paradox phenomenon [2]. It is known that many multiparous women develop antibodies against IPA of the child [6]. It is possible that after maternal graft

Correspondence to: Rabab A Al Attas, Histocompatibility and Immunogenetic Laboratory (HIL), Department of Pathology and Laboratory Medicine, King Fahad Specialist Hospital-Dammam, Saudi Arabia, E-mail: Rabab.Attas@kfsh.med.sa

Key words: ESRD, non-inherited maternal antigen (NIMA), inherited paternal antigens (IPA), Chimerism, Graft tolerance, HLA, donor specific alloantibodies (DSA), single antigen beads (SAB)

Received: April 14, 2017; Accepted: May 01, 2017; Published: May 03, 2017 
transplantation antigen presenting cells (APC) from the graft will recognize IPA of the recipient when the mother is the donor, however when the sibling is the donor the graft derived -cells will only recognize IMA that they encountered during fetal life, so possibly that the anti-IPA maternal response (donor) is responsible for undermining tolerance to NIMA. Another difference between maternal-derived graft and sibling derived graft is the fact that a maternal -derived graft can be seen as a second confrontation (the first encountered during pregnancy). In contrast a graft derived from sibling is a primary confrontation towards most of the antigens. These factors may influence the immunological response; therefore contribute to the fact that maternal grafts do not do better as sibling -derived graft (NIMA paradox) [7-9].

We describe here a case of successful second transplant due to persistence immune tolerance to NIMA despite repeated exposure to maternal antigens. The second graft was from a sibling- who shared NIMA with a failed first maternal - derived graft.

\section{Case history}

A 26-year-old female with ESRD had her first kidney transplant from her mother in 2011. Her graft failed over the next two years due to chronic rejection. Her brother offered the second graft. HLA- typing for the patient and her two donors (the mother and the brother) is represented in Table 1. During the second transplant work up, her investigation showed positive HLA-Class II antibody screening only. Antibody identification by single antigen bead (SAB) on Luminix platform revealed weak DQ2 specificity of 600 mean fluorescent intensity (MFI) (Figure 2), which was interpreted as donor specific antibody (DSA) to the first donor, due to DQ2 antigen mismatch. HLATyping of the new donor (her brother) showed sharing of DQ2 antigen

Table 1. HLA-Typing. with the first graft (mother) but FXM was negative for both $\mathrm{T}$ and $\mathrm{B}$ cells with the second donor. Patient proceeded to a Thymoglobulin induced second transplant in February 2014 from her brother. The first routine post-transplant $\mathrm{SAB}$ results showed remarkable increase in DQ2, MFI of 11380 (Figure 3). The treating nephrologist was alerted by us, and the patient was put under close surveillance, including repeating DSA tests despite normal serum creatinine level. A kidney biopsy was also performed and showed mild tubular injury in some tubules, with negative C4d staining. Because of the persistence elevation of DSA and in view of normal kidney function, the treating team kept questioning the antibody results. While having a stable normal serum creatinine, a second biopsy was obtained which showed the same previous histological findings, but with C4d focally positive. At this time, the patient received pulse steroids, five sessions of plasma exchange, intravenous immunoglobulin, and a single dose of Rituximab.

Follow up DSA levels remained unchanged over the subsequent three weeks. As a result, patient and donors' HLA data were reanalyzed, including performing DQ high resolution (HR) typing.

HR typing confirmed HLA- $\mathrm{DQB1}^{\star} 02: 02$ associated with $\mathrm{DQA}^{\star}{ }^{\star 02: 01}$ for both donors. But careful analysis of antibody revealed that the high antibody was non-donor specific. It was directed against a subgroup of DQ2 (HLA-DQB1 ${ }^{\star} 02: 01$ associated with $\mathrm{DQA}^{\star} 05: 01$ ) (Figure 4). So an amended report was issued with the correct assignment of absent of donor specific antibody. The patient is now three years post-retransplant with very good renal function.

\section{Discussion}

Due to the increasing number of highly sanitized patients that

\begin{tabular}{|l|c|c|c|r|r|}
\hline & A & B & C & DRB1 & DQA1 \\
\hline Patient & 23,33 & 42,14 & 08,17 & 03,01 & 01,04 \\
\hline D1 (Mother) & $23,-$ & $42, \mathbf{5 0}$ & 06,17 & 03,07 & 02,04 \\
\hline D2 (Brother) & $03, \mathbf{2 3}$ & $27, \mathbf{5 0}$ & $\mathbf{0 6}, 02$ & 11,07 & $\mathbf{0 2}, 05$ \\
\hline
\end{tabular}

The highlighted antigens are the repeat mismatch presented on the non-inherited maternal haplotype

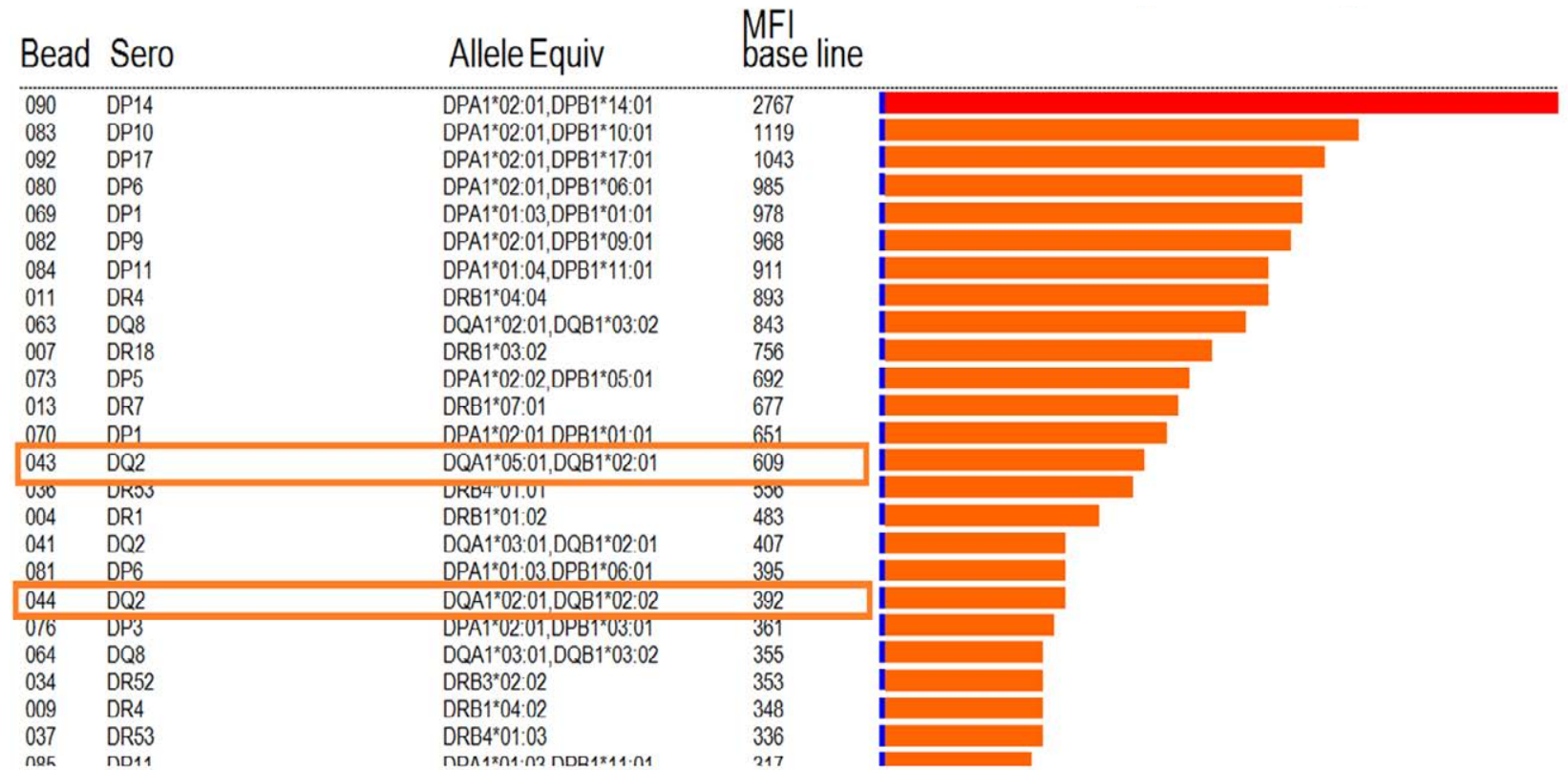

Figure 2. Single AntigenBead (SAB) reactivity panel showing Antibodies against HLA Class II single-antigen for pre-transplant sample. The most left portion represents bead number (Bead). Serologic equivalents are provided under the column labeled "Sero". Allele Equivalents in the middle represent variable DQ $\alpha \beta$ combinations for each bead. The most right portion represents a column chart of the median fluorescence intensity (MFI). The square marks the weak reactivity DSA. 


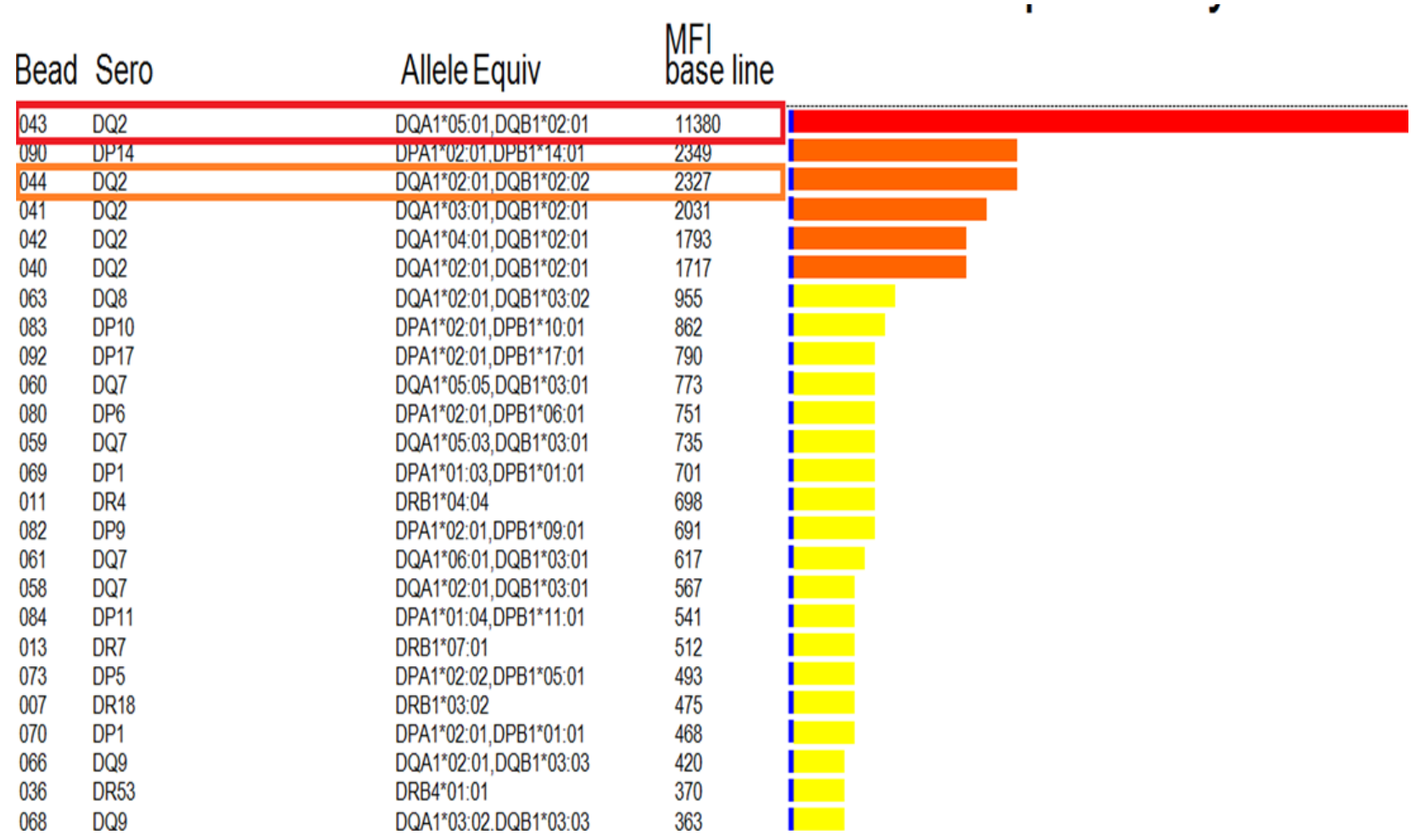

Figure 3. Single antigenBead (SAB) reactivity panel showing Antibodies against HLA Class II single-antigen in post-transplant sample. The most left portion represents bead number (Bead). Serologic equivalents are provided under the column labeled "Sero". Allele Equivalents in the middle represent variable DQ $\alpha \beta$ combinations for each bead. The most right portion represents a column chart of the median fluorescence intensity (MFI).The square marks the positive DQ2 carrying beads.

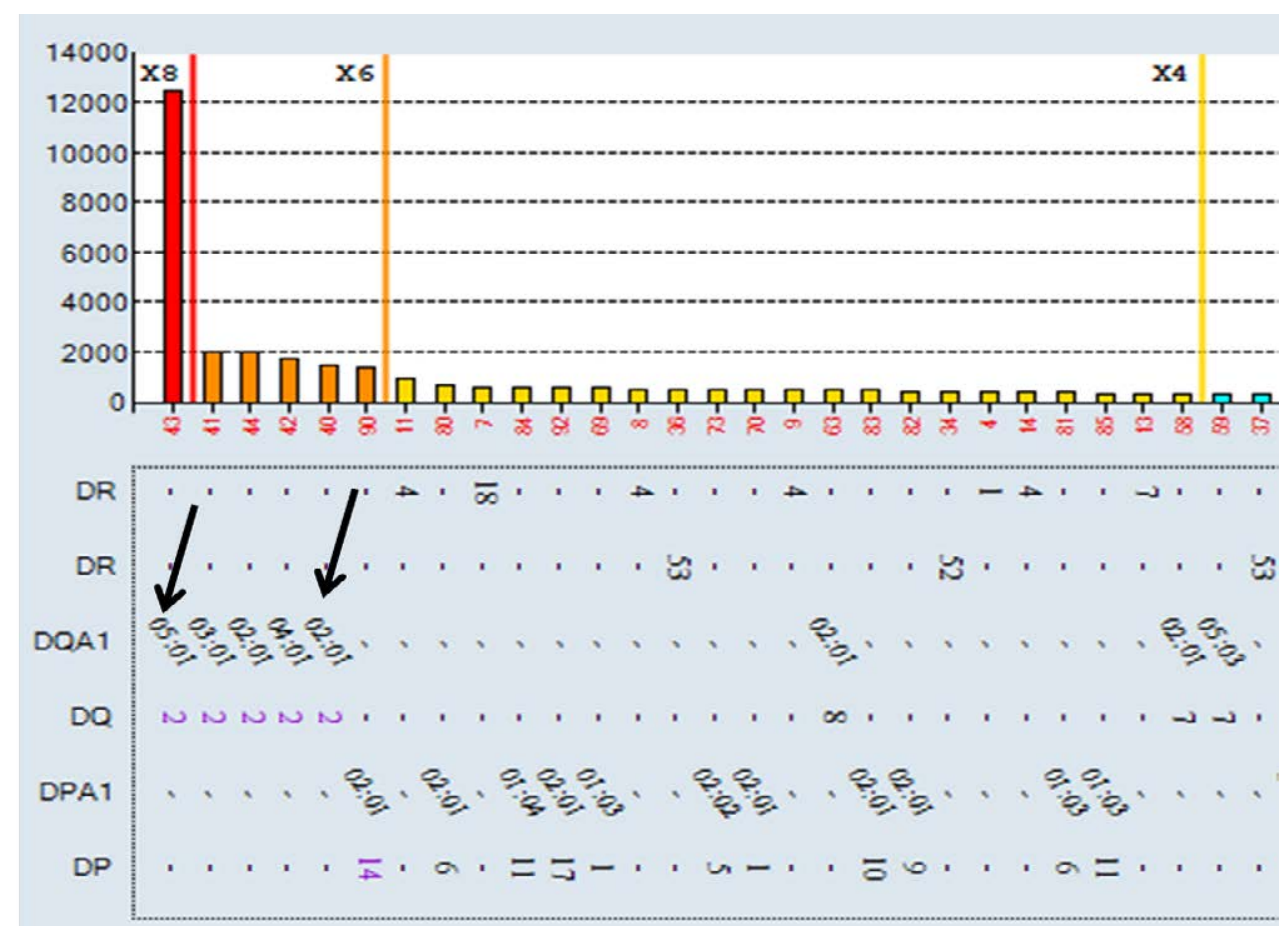

Figure 4. Anti-class II specificity chart when both DQ $\alpha, \beta$ chains are analyzed. The first arrow shows the positive DQ2 bead combined with DQA 05:01. The second arrow points to the correct weak DSA where the DQ2 bead has different $\alpha$-chain.

are difficult to match and transplant "acceptable mismatch" scheme was developed. In this context it was observed that highly immunized patients formed antibodies significantly less often against the NIMA $[7,9]$ therefore patient transplanted with such kind of mismatch are considered acceptable mismatch and might be immunosuppressed differently.

The detrimental effect of HLA Class II -antibodies directed against allograft antigens on transplantation outcome is well established [10-12]. 
The significance of the DQ antibodies is increasingly recognized following the introduction of the SAB assay which considered today to be the most sensitive and specific method for alloimmunization assessment [13-15]. However, it is becoming clear that the detection of the HLA antibodies by SAB is not absolutely perfect due to the variation in densities and orientations of the antigen coated beads [1618 ]. HLA-DQ antigen consists of two $(\alpha \beta)$ polymorphic chains [19]. Consequently both chains can induce immunologic response. Routine $\mathrm{SAB}$ testing approach, which assigns the specificities based on beta chains and ignores the contribution of the DQa chains, can lead to erroneous DQ -antibody assignments. Therefore, analysis of the DQ HLA antibodies quite often misleading by using the current serological definition $[20,21]$. Our report of strong DSA have disadvantaged this patient when, in reality, she only had weak level of DSA.

Several studies showed that maternal kidney graft have no improved graft survival with no advantageous effect of NIMA compared to NIMA effect from sibling. Several explanations were given for these phenomena $[2,8,9]$, however, the exact mechanism underlying these phenomena is still not revealed. Our case is a further confirmation for this phenomenon by presenting an interesting combination for the same NIMA that has no advantageous impact in the first transplant when presented on maternal graft but demonstrated sustained tolerance to repeat mismatched NIMA when presented by the sibling donor. This case has encompassed both the NIMA paradox where the NIMA- carrying maternal graft did not offer survival benefit for the first graft, while the same NIMA -offered tolerance advantage when presented on the second sibling-derived graft. We believe that this case should be a model to study further the different effect of NIMA to reveal the underlying mechanism. It further addresses the optimal selection of donor in presence of different haplotype mismatch options.

In conclusion better recognition of the beneficial effect of NIMA and careful assignment of HLA- DQ-antibody are both important for better donor selection and patient management.

\section{References}

1. Burlingham WJ, Grailer AP, Heisey DM, Claas FH, Norman D, et al. (1998) The effect of tolerance to noninherited maternal HLA antigens on the survival of renal transplants from sibling donors. N Engl J Med 339: 1657-1664. [Crossref]

2. van den Boogaardt- Danielle EM, Rood JV, Roelen DL, Class FHJ (2006) The influence of inherited parental antigens on outcome after transplantation. Transplant Int 19:360371. [Crossref]

3. Evans PC, Lambert N, Maloney S, Furst DE, Moore JM, et al. (1999) Long term fetal michrochimerism in peripheral blood mononuclear cell subsets in healthy women and women with scleroderma. Blood 93: 2033-7. [Crossref]
4. Ichinohe T, Teshima T, Matsuoka K, Maruya E, Saji H (2005) Fetal-maternal microchimerism: impact on hematopoietic stem cell transplantation. Curr Opin Immunol 17: 546-552. [Crossref]

5. Opelz G (1990) Analysis of the "NIMA effect" in renal transplantation. Collaborative Transplant Study. Clin Transpl. [Crossref]

6. Van Kampen CA, Versteeg-van der Voort Maarschalk MF, Langerak- Langerak J, van Beelen E, Roelen DL, et al. (2001) Pregnancy can induce long-persisting primed CTLs specific for inherited paternal HLA-antigens. Human Immunol 62: 201. [Crossref]

7. Claas FH, Gijbels Y, van der Velden-de Munck J, van Rood JJ (1988) Induction of B cell unresponsiveness to noninherited maternal HLA antigens during fetal life. Science 241: 1815-1817. [Crossref]

8. Burlingham WJ, Benichou G (2012) Bidirectional alloreactivity: A proposed microchimerism-based solution to the NIMA paradox. Chimerism 3: 29-36. [Crossref]

9. van Rood JJ, Roelen DL, Claas FH (2005) The effect of noninherited maternal antigens in allogeneic transplantation. Semin Hematol 42: 104-111. [Crossref]

10. Campos EF, Tedesco-Silva H, Machado PG, Franco M, Medina-Pestana JO, et al (2006) Post-transplant anti-HLA class II antibodies as risk factor for late kidney allograft failure. Am J Transplant 6: 2316-2320. [Crossref]

11. Duquesnoy RJ (2008) Human leukocyte antigen class II antibodies and transplant outcome. Transplantation 86: 638-640. [Crossref]

12. Terasaki P, Mizutani K (2006) Antibody mediated rejection: update 2006. Clin J Am Soc Nephrol 1: 400-403. [Crossref]

13. Almeshari K, Pall A, Elgamal H, Alzayer F, Alawwami M (2011) HLA-DQ antibodies are the most frequent antibodies encountered in antibody mediated rejection (AMR) of renal allograft. Human Immunol 72: 187.

14. Willicombe M, Brookes P, Sergeant R, Santos-Nunez E, Steggar C, et al. (2012) De novo DQ donor-specific antibodies are associated with a significant risk of antibodymediated rejection and transplant glomerulopathy. Transplantation 94: 172-177. [Crossref]

15. DeVoes JM, Gaber AO, Knight RJ, Land GA, Suki WN, et al. (2012) Donor - specific HLA-DQ antibodies may contribute to poor graft out come after renal transplantation. Kidney Int 82: 598-604. [Crossref]

16. Gombos P, Opelz G, Scherer S, Morath C, Zeier M, et al. (2013) Influence of test technique on sensitization status of patients on the kidney transplant waiting list. $\mathrm{Am} \mathrm{J}$ Transplant 13: 2075-2082. [Crossref]

17. Middleton D, Jones J, Lowe D (2014) Nothing's perfect: the art of defining HLAspecific antibodies. Transpl Immunol 30: 115-121. [Crossref]

18. Zachary AA, Vega RM, Lucas DP, Leffell MS (2012) HLA antibody detection and characterization by solid phase immunoassays: methods and pitfalls. Methods Mol Biol 882: 289-308. [Crossref]

19. Mach B (1994) Genetics of histocompatibility. Curr Opin Hematol 1: 4-11. [Crossref]

20. Tambur AR, Leventhal JR, Friedewald JJ, and Ramon D (2010) The complexity of HLA-DQ antibodies and its effect on virtual crossmatching. Transplantation 90: 111724. [Crossref]

21. Al Attas R, Al Abduladheem D, Shawhatti AA, Lopez R, Liacini A, et al. (2015) The dilemma of DQ HLA-antibodies. Hum Immunol 76: 324-328. [Crossref]

Copyright: $(02017 \mathrm{Al}$ Attas RA. This is an open-access article distributed under the terms of the Creative Commons Attribution License, which permits unrestricted use, distribution, and reproduction in any medium, provided the original author and source are credited. 